\title{
O Que se Pode Ver da Janela: \\ Uma Análise do Subprojeto de \\ Letras-Jnglês do Programa PJBJD
}

\author{
What Can Be Seen from the Window: An Analysis of an \\ English Language Teacher Program
}

\section{Elaine Fernandes MATEUS* Michele Salles EL KADRI** Pricila GAFFURI***}

Resumo: Este trabalho tem como objetivo lançar um olhar a partir da janela sócio-histórico-cultural para compreender o(s) sentido(s) de colaboração expressos no texto do subprojeto de Letras-Inglês, da Universidade Estadual de Londrina, do Programa Institucional de Bolsas de Iniciação à Docência (PIBID). A análise revela que a iniciativa representa: a) a continuidade de modelos de formação inicial e contínua de professores de Inglês vivenciados pela Instituição e agora formalizados nesta proposta governamental; b) possibilidades para o fortalecimento de uma cultura colaborativa na formação de professores e; c) uma resposta às demandas de melhoria da qualidade dos cursos de formação, do ensino na educação básica e dos contextos nos quais as comunidades escolares estão inseridas. $\mathrm{O}$ apagamento dos papeis do formador, tomados, por esta razão, como dados e imutáveis revela um padrão complementar de colaboração e convida a refletir sobre o desafio da mutualidade no trabalho colaborativo.

* Doutora em Linguística Aplicada e Estudos da Linguagem, pela Pontifícia Universidade Católica de São Paulo, 2005. Professora Adjunta da Universidade Estadual de Londrina. Contato: mateus@uel.br

** Doutoranda em Estudos da Linguagem, na Universidade Estadual de Londrina. Professora Assistente da Universidade Estadual de Londrina. Contato:misalles@yahoo.com.br

*** Mestranda em Estudos da Linguagem, na Universidade Estadual de Londrina.Contato: pricila_gaffuri@hotmail.com 
Palavras-chave: Colaboração; Formação de professores de inglês; PIBID.

Abstract: Looking through the socio-cultural-historical window, this paper aims at investigating an ELT subproject from Universidade Estadual de Londrina inserted into a governmental program, in order to understand the collaboration meaning(s) there expressed. The analysis revels: a) the continuity of models of initial and continuous English teacher education experienced by the Institution and now formalized in the public policy initiative; b) possibilities for strengthening a collaborative culture in teacher education and; c) an answer to demands regarding the need of improvement not only in the ELT courses but also in the basic education curriculum and in the context in which school communities are located. The blurring of the teacher educators' roles taking, as such, for granted and as immutable reveals a complementary collaboration pattern and leads to a reflection regarding the challenges of mutuality in collaborative practices.

Key-words: Collaboration; English language teacher education; PIBID.

A diferença se encontra no lugar onde os olhos são guardados.

Rubem Alves A complicada arte de viver

\section{Introdução}

A formação de professores tem sido historicamente tematizada sob variadas perspectivas. Os sentidos de ser professor podem ser compreendidos à luz da tradição da eficiência social ou técnica (FEIMAN-NEMSER, 1990), da racionalidade prática (SCHON, 1987), da orientação crítico-social (VADEBONCOEUR, 1997), da perspectiva do desenvolvimento sociocultural (JOHNSON, 2006). Cada uma dessas janelas permite contemplar lugares únicos e têm guardadas em si as riquezas do olhar irrepetível.

Assim é a proposta desse texto: lançar um olhar a partir da janela sócio-histórico-cultural para compreender o(s) sentido(s) de colaboração expressos(s) no texto do subprojeto de Letras-Inglês, da 
Universidade Estadual de Londrina, do Programa Institucional de Bolsas de Iniciação à Docência (PIBID), anunciado no Edital CAPES 018/2010, em que são explicitados os objetivos, o plano de trabalho, as ações previstas, os resultados pretendidos e o cronograma das atividades. Não pretendemos, desse modo, o olhar absoluto, mas aquele que assume a responsabilidade pelo acabamento do que contempla.

É certo que, ao escolhermos, guardamos nossos olhos neste lugar, como ensina Rubem Alves, nos comprometemos com uma epistemologia dialética de ser humano que forja e, ao mesmo tempo, é forjado no interior de práxis mediada por discursos, situada culturalmente, valorizada socialmente e distribuída entre pessoas, no tempo. Isso significa dizer que partimos do pressuposto de que as experiências vividas pelos sujeitos ao longo de suas vidas desenham o espectro de possibilidades no devir de cada um, com todos; possibilidades essas, portanto, que não existem em si mesmas, mas que são mediadas pelas condições dominantes (ROTH; TOBIN, 2004).

Começamos a discussão com uma revisão crítica sobre o conceito de colaboração e sobre práticas colaborativas de formação de professores de inglês. Nosso interesse recai sobre aquilo que define práxis colaborativa voltada à transformação de realidades sociais. Em seguida, analisamos os movimentos históricos que têm influenciado políticas de formação de professores voltadas ao estreitamento das relações entre universidades e escola. Nesse ponto, nos concentramos no PIBIB como uma dessas propostas desenhadas para superar a dicotomia entre teoria e prática para, então, apresentarmos e analisarmos o texto do subprojeto de Letras-Inglês da UEL. Ao longo da análise de conteúdo, de base interpretativista, buscamos compreender o(s) sentido(s) de colaboração ali presentes, a partir dos modos como se definem os papéis dos participantes. Com base nas condições dominantes, inferimos o espectro de possibilidades a eles dadas.

Esperamos que essa discussão possa contribuir para uma reflexão acerca da reificação de conceitos que podem, em última análise, levar ao esvaziamento de sentidos e à esterilidade da ação. Desejamos, ainda, que esse texto tencione as complexidades envolvidas na colaboração que visa à criação de mutualidade e de interdependência produtiva (JOHN-STEINER, 2000). 


\section{Alguns sentidos de colaboração}

A descoberta pelo mundo ocidental dos estudos de Vigotski, a partir da década de 80, foi decisiva no processo de restabelecimento das relações sociais que dão acesso à cultura como o elemento central para o desenvolvimento da espécie. O ser humano é, por natureza, constituído por aquilo que é externo a ele mesmo, que é outro. O modo como nos tornamos, o nosso devir, é senão uma possibilidade da nossa inter-relação com o outro. "É por meio do outro que nos reconhecemos como sujeitos e recriamos nossas identidades profissionais, raciais, sexuais, étnicas, religiosas e incontáveis outras que se forjam no interior das relações que vivemos" (MATEUS, 2009, p. 315). Segundo Moita Lopes (1996, p. 6), "é a presença do outro com quem interagimos que, em última análise, nos faz ser quem, como e por que somos através do envolvimento no discurso".

Assim, a colaboração constitui o estatuto ontológico de ser humano. Como homens e mulheres, existimos na relação com o outro sendo partes de comunidades ao mesmo tempo em que as constituímos, um implicado no outro, como um e como muitos, simultaneamente.

Partindo dessa premissa, nas últimas décadas, pesquisadores têm voltado seus interesses para os modos como a colaboração se liga ao desenvolvimento cognitivo, afetivo e emocional das pessoas. As metáforas mais comumente utilizadas nos campos da antropologia, ciências sociais, educação e linguística aplicada para se referir ao conceito de trabalho colaborativo são as de comunidade e de parceria.

No entanto, se, por um lado, o foco sobre os trabalhos colaborativos pode ser compreendido como catalisador de transformações, por outro, a reificação do conceito pode levar ao seu esvaziamento. Com o advento do modo de produção volvista no início deste século, o termo comunidade passou a ser amplamente utilizado em várias formações discursivas. Uma busca simples na rede mundial de computadores revela a ocorrência do termo em aproximadamente 169 milhões de entradas. Comum aos mais variados sentidos está o fato de que comunidades envolvem pessoas. Assim, considerando que nossas possibilidades de ação são mediadas pelos discursos dominantes e sentidos que atribuímos às práticas em que nos 
envolvemos, faz-se fundamental marcar nossos sentidos próprios de colaboração, sentidos estes que se configuram a partir dos lugares em que guardamos nossos olhos e que orientam nossa compreensão de ser humano.

Há, na literatura educacional, um bom número de pesquisadores envolvidos na tarefa de dar sentidos ao trabalho conjunto. Como esta breve discussão deixará ver, não é possível presumir consenso nem mesmo no interior de estudos considerados sócio-histórico-culturais; aqui também o conceito de colaboração é entendido, por alguns, numa relação de opostos e opositores, centro e periferia, expert e novato, mais experiente e menos experiente e, por outros, numa relação dialética entre o individual-coletivo, singular-plural, permanência-transformação.

Com foco no ambiente escolar, Perrenoud (2001), embora use os termos colaboração, cooperação, ação coletiva e trabalho em equipe inter-relacionadamente, apresenta uma distinção inequívoca entre pseudoequipes - constituídas a fim de compartilhar um espaço, por exemplo, mas sem que seus membros tenham algum tipo de envolvimento entre si; equipes lato sensu - compostas por pessoas interessadas em trocar ideias, se ajudar mutuamente, mas sem qualquer tipo de imposição aos seus participantes; e as equipes stricto sensu formadas por um grupo interessado em agir junto, em colaborar num mesmo trabalho. Para ele, a colaboração estaria presente nesse último tipo de arranjo, em que o foco se mostra no gerenciamento coletivo das responsabilidades pela aprendizagem dos mesmos alunos.

Também Fullan e Hargreaves (2000) utilizam vários termos para se referir à colaboração na escola: trabalho colegiado, sistema de parceria, sistema de coletividade, cultura cooperativa. Contudo, a percepção sobre o que seja colaboração está próxima àquela discutida por Perrenoud (2001), já que, para Fullan e Hargreaves (2000), o trabalho colaborativo implica em compartilhar responsabilidades, em comprometer-se com o aperfeiçoamento coletivo, em discutir questões críticas e intrigantes. Para eles, as colaborações efetivas só acontecem quando são contemplados os princípios que buscam a transformação da sala de aula.

A distinção entre a natureza inerentemente colaborativa das interações humanas e o trabalho colaborativo com vistas à autonomia e emancipação dos participantes contribui para a definição do estatuto 
da colaboração numa perspectiva sócio-histórico-cultural. Assim tomadas, as práticas colaborativas se configuram como processos criativos (ENGESTRÖM, 1999), ou seja, como alternativas para a solução dos conflitos vividos nos contextos educacionais historicamente desiguais e autoritários. Nesta perspectiva, a atividade do trabalho colaborativo deve ter como objeto a produção do conhecimento, por meio de um processo em que todos aprendam "a criticar, a ver mais claramente, a pensar num nível mais elevado, a reconhecer a forma como suas consciências são socialmente construídas" (KINCHELOE, 1997, p. 181), ao mesmo tempo em que desenvolvem práticas sociais como a "tolerância, a paciência, a descentralização, a resistência aos conflitos, a capacidade de escuta” (PERRENOUD, 2001, p. 129).

Nesta mesma direção, Vera John-Steiner, em seu livro Creative Collaboration, publicado em 2000, descreve a natureza psicológica de diferentes padrões de colaboração decorrentes de parcerias artísticas, afetivas e intelectuais. A autora traça limites entre trabalhos cooperativos - definidos como aqueles nos quais cada um dos participantes traz contribuições específicas para uma determinada tarefa - e atividades colaborativas - caracterizadas como aquelas nas quais há maior equidade de papéis e responsabilidades entre os participantes envolvidos em uma tarefa comum.

Nesse sentido, John-Steiner (2000) argumenta que a colaboração pode variar de acordo com a intensidade, a duração do processo e os objetivos de cada grupo e distingue, com base nestes critérios, quatro padrões de colaboração:

- colaboração distribuída, em que os participantes têm interesses similares, trocam informações em conferências e listas eletrônicas, exploram pensamentos e opiniões, assumem papéis informais e voluntários, mas que, por não conseguirem trabalhar de maneira produtiva com o conflito, deixam a parceria quando surgem controvérsias;

- colaboração complementar, em que os participantes têm valores que se sobrepõem, negociam objetivos, buscam uma visão comum e promovem uma divisão clara do trabalho baseada na complementariedade da expertise, do conhecimento e dos papéis, por meio de uma abordagem centrada na disciplina e cumprimento das regras pré-definidas; 
- colaboração familiar, em que os participantes partilham de uma visão comum, confiam uns nos outros, permitindo, assim, a flexibilidade e a dinamicidade na divisão do trabalho, marcada principalmente pela confiança, responsabilidade e ajuda mútua; e

- colaboração integrativa, em que os participantes compartilham o desejo de transformação de uma prática, a disponibilidade da realização em longo prazo, o diálogo e os esforços com vistas à superação do conflito, das diferenças de opinião e à promoção do outro. Neste padrão de colaboração, são essenciais as vivências do interesse comum apaixonado, da escuta cuidadosa, do envolvimento emocional, dos propósitos compartilhados, da apropriação mútua, da ética da responsabilidade individual pelo bem comum e dos processos contínuos de resolução de conflitos e tensões.

Não se deve supor, com isto, que um padrão de colaboração seja melhor do que o outro. O que se pretende compreender é que as pessoas podem se engajar em diferentes níveis de colaboração dependendo dos motivos que as impulsionam e, com isso, alcançar diferentes resultados. Cada qual com seus valores, métodos de trabalho e papéis assumidos, guardam e revelam em si o pressuposto de que estar com o outro nos leva a caminhos de possibilidades aos quais não podemos chegar sozinhos. Ademais, estes níveis de colaboração não são fixos, estáveis; pelo contrário, são processos dinâmicos, contínuos, que se transformam ao longo das interações, assim como nossas relações com outras pessoas transformam-se cotidianamente, levando-nos a movimentos de aproximação e de afastamento, pois "a realização de colaborações produtivas requer tempo e esforço sustentados; requer a modelagem de linguagem compartilhada, os prazeres e os riscos do diálogo honesto e a busca de bases comuns" (JOHN-STEINER, 2000, p. 204).

Nossa compreensão, diante destas muitas janelas, repousa sobre sentidos de colaboração que envolvem participantes em ações de negociação contínua (CAMERON et al., 1992; COLE; KNOWLES, 1993; MCLAREN; GIROUX, 2000; MAGALHÃES, 2010), a partir de questionamentos sobre desigualdades sociais e culturais em que se inserem (PENNYCOOK, 1994), com vistas à transformação desses 
contextos (BREDO; FEINBERG, 1982; COLE; KNOWLES, 1993; PENNYCOOK, 1994; FULLAN; HARGREAVES, 2000), bem como à quebra do monopólio na produção dos conhecimentos (CAMERON et al., 1992; COLE; KNOWLES, 1993; AUERBACH, 1994; PENNYCOOK, 1994; MATTOS, 1995). Assim, porquanto a colaboração seja inexorável para o desenvolvimento humano, nos filiamos aos sentidos de práticas colaborativas mediadas pelo desejo, mutualidade, complementariedade, confiança, humildade, paixão, diferença, conflito.

Assim como para Holzman e Karliner (2005, p. 1), nossa práxis se orienta por sentidos de colaboração como "um processo criativo e coletivo de pessoas que dão vida a novas unidades sociais e compartilham um compromisso coletivo para sua sustentabilidade". Sentidos, portanto, de colaboração como "atividade criativa, em devir, aberta a todos que queiram participar”.

\section{Práticas colaborativas e a formação de professores}

Como dissemos, os últimos 20 anos têm sido marcados por estudos que visam a compreender os modos como práticas colaborativas se ligam aos processos de desenvolvimento humano. $\mathrm{Na}$ área de formação de professores, a década de 90 vivenciou a chamada "virada sociocultural" (JOHNSON, 2006) e viu florescer estudos que buscam lançar luz sobre os modos como professores aprendem, em colaboração uns com os outros. A epistemologia sócio-histórico-cultural define aprendizagem como prática social dinâmica, em constante devir, situada em contextos próprios, mediada por artefatos e distribuída entre os participantes (VIGOTSKI, 1962; 1978; 1997; 1998; LEONTIEV, 1959; 1978; 1998). Isso significa dizer que o desenvolvimento do indivíduo forja-se no interior e a partir da vida social e que os sentidos não residem na linguagem por si, mas nos usos que os grupos culturais fazem dela (JOHNSON, 2009).

Tomada nesta perspectiva, a aprendizagem de professores experimenta alguns outros desafios. Dentre eles, Johnson (2006; 2009) destaca a necessidade de se criar oportunidades para o rompimento da dicotomia teoria-prática, para a legitimidade dos modos de produção do conhecimento dos professores, para a redefinição das 
fronteiras do desenvolvimento profissional, para o reconhecimento da inter-relação entre os contextos sociais no interior dos quais os professores existem e suas possibilidade de ser, e para a compreensão da relação entre o desenvolvimento de professores e a aprendizagem dos alunos. No conjunto, estes desafios têm forjado práticas de formação que buscam criar estruturas alternativas com vistas à transformação das realidades sociais.

Desde 2002, temos nos dedicado a promover espaços de aprendizagem como processo colaborativo de ressignificação de práxis sociopedagógica e de identidades profissionais (MATEUS; PEZENTE; ROSA 2003; MATEUS, 2004; 2005; 2006; 2007; 2009a; 2010; MATEUS; PICONI, 2007; 2009; EL KADRI; MATEUS; PASSONI, 2009; GIMENEZ; MATEUS, 2009; GAFFURI; MATEUS, 2010). Ao longo de nossas experiências, temos aprendido que, se por um lado, a redefinição das fronteiras em que as aprendizagens se dão é condição para a agentividade de professores e para transformação das práticas culturais educacionais, por outro, novos modelos não implicam ipso facto a superação das contradições que medeiam os processos. Sabemos que são os tipos de participação engendrados nestes modelos híbridos e as possibilidades de criação de sentidos neles criadas que, em última instância, determinam o espectro de ação, de transformação e de desenvolvimento.

\section{Políticas públicas de formação de professores e o PIBID}

Assim como na literatura da área, o discurso de colaboração, de comunidade e de parceria tem prevalecido nos documentos recentes produzidos pelas Secretarias de Educação. Apropriando-se de formações discursivas gestadas no interior de práticas de pesquisa como as anteriormente mencionadas, as políticas de governo do início desse século têm gerado investimentos públicos voltados à melhoria da educação de professores e, consequentemente, do ensino básico. Impulsionadas pelos resultados das avaliações da qualidade do ensino da rede pública e pelos pressupostos socioculturais, tais documentos têm tentado reconceitualizar a formação de professores e provocado movimentos que visam a aproximar escola-universidade, teoria-prática. 
Nesta direção, o Ministério de Educação e Cultura (MEC) lança programas de formação de professores como o Programa de Desenvolvimento Educacional (PDE), o Programa de Consolidação das Licenciaturas (PRODOCÊENCIA e o Programa Institucional de Bolsas de Iniciação à Docência (PIBID)). Embora cada um preserve sua especificidade, estas iniciativas compartilham o objetivo de fortalecer as licenciaturas e parecem ter em comum a premissa de que universidade e escola devem caminhar juntas no desenvolvimento profissional do professor.

O PIBID, foco desta discussão, é um programa de formação que está em sua $3^{a}$ edição e que oferece bolsa para estudantes de cursos de licenciatura plena, para que eles exerçam atividades pedagógicas em escolas públicas de ensino básico, a fim de aprimorar a sua formação e contribuir para a melhoria da qualidade do ensino dessas escolas. Tem como objetivos principais a elevação da qualidade das ações acadêmicas voltadas à formação inicial de professores, assim como promover a integração entre a universidade e a educação básica, buscando articular a teoria e a prática. Além de promover a inserção dos futuros professores no cotidiano de escolas da rede pública de educação, o PIBID visa também a "proporcionar aos futuros professores participação em experiências metodológicas, tecnológicas e práticas docentes de caráter inovador e interdisciplinar e que busquem a superação de problemas identificados no processo de ensinoaprendizagem" (CAPES, 2010, p. 3). Objetiva, ainda, incentivar as escolas públicas da educação básica a se tornarem protagonistas dos processos formativos dos estudantes das licenciaturas, mobilizando seus professores como coformadores dos futuros professores.

\section{$4 \mathrm{O}$ subprojeto de Letras-Inglês: de que colaboração falamos?}

O curso de Letras Estrangeiras Modernas - Inglês, da Universidade Estadual de Londrina, tem construído e vivenciado, por meio de projetos, uma trajetória de formação colaborativa de professores em que os pressupostos da perspectiva sócio-históricocultural são considerados a partir de diferentes configurações e sentidos. Projetos como: Ação e Reflexão na Formação do Professor de Lingua Inglesa (REIS, 1999); Aprendizagem sem Fronteiras: ressignificando os limites da formação 
inicial e continua de professores (MATEUS, 2009b); e Parceria UniversidadeEscola (ORTENZI et al., 2004; FURTOSO et al., 2009), vinculados ao Programa NAP (GIMENEZ, 1999; MATEUS; QUEVEDOCAMARGO; GIMENEZ, 2009), têm trazido importantes contribuições tanto para a formação inicial quanto contínua de professores. Estamos convencidas de que tais projetos constituem-se células embrionárias de práticas dialógicas que se reconfiguram na iniciativa do PIBID.

Já em seu título - Formação colaborativa de professores e inovação curricular no ensino da língua inglesa - o subprojeto sinaliza uma concepção de formação de professores que se aproxima de práticas pautadas no trabalho conjunto. Não somente isso. A proposição de que a colaboração entre professores deve visar à transformação produz possibilidades de uma proposta de intervenção situada nos espaços escolares e, portanto, a partir deles.

O plano do subprojeto pretende atuar em dois eixos principais: na elevação da qualidade da formação de professores (por meio da criação de espaços colaborativos para o planejamento, a execução e a avaliação do processo de ensino-aprendizagem de língua inglesa) e na inovação curricular do ensino de língua inglesa (por meio da transposição didática das OCEM). Embora estes espaços colaborativos permeiem o discurso do planejamento, da execução e da avaliação do processo de ensino-aprendizagem de língua inglesa, ancorando-se, assim, nas tendências contemporâneas que posicionam o fortalecimento do vínculo entre escola e universidade como modelo de formação de professores em que teoria e prática se reconstroem mutuamente, o subprojeto não define de forma esclarecedora como seriam organizados esses espaços colaborativos e quem participaria deles. Apontamos anteriormente, com base na literatura, que estar juntos não configura, por si, padrões integrativos de colaboração.

$\mathrm{Na}$ epistemologia sócio-histórico-cultural, espaços colaborativos são "zonas de ação um tanto desconfortáveis" (JOHN-STEINER, 2000, p. 82). A uma, porque o trabalho no contexto escolar é visto como uma prática individual e as questões sociais, históricas e culturais são pouco consideradas nas discussões. A duas, porque as práticas discursivas organizadas ao redor da argumentação não são comuns na escola. 
Ancorado nos dois eixos descritos acima, o subprojeto propõese a desenvolver ações voltadas para a inserção dos bolsistas de iniciação à docência no contexto escolar e para a construção coletiva de práticas pedagógicas de caráter inovador a serem implementadas colaborativamente na realidade escolar. Mais especificamente, o documento lista os seguintes propósitos:

Promover grupos de estudos semanais envolvendo professores supervisores e bolsistas de iniciação à docência voltados ao conhecimento e análise do contexto e ao desenvolvimento de práticas de inovação curricular; Promover a discussão e a transposição didática das novas orientações curriculares para o Ensino Médio para o sistema didático;Fomentar o desenvolvimento de práticas de ensino colaborativo envolvendo professores supervisores e bolsistas de iniciação à docência;Gerar conhecimento contextualizado através de práticas investigativas. (Subprojeto)

O primeiro elemento que se destaca na leitura deste trecho do documento diz respeito ao papel do professor da escola, tradicionalmente colocado como responsável por controlar o acesso de estagiários em sua sala e aqui renomeado como professor supervisor, papel historicamente concedido ao professor formador que atua na universidade. Esta renomeação de papéis se repete quando o documento define como parte da metodologia de trabalho a constituição de "grupos de estudos com os professores supervisores para discussão de seu papel como co-formador" sendo, ao longo do subprojeto, o professor da universidade denominado de formador e, eventualmente, de coordenador. Tomando a linguagem como prática social (FAIRCLOUGH, 1989), é possível considerar que os impactos da renomeação do professor da educação básica como professor supervisor devem se fazer sentir nos modos como os participantes posicionam suas identidades e promovem transformações no modelo de formação. Por outro lado, o conceito de professor supervisor traz em si o significado que mantém presente a relação hierárquica deste com o professor novato, aqui nomeado como bolsista de iniciação à docência. 
O segundo aspecto de nossa análise se refere ao próprio sentido de inovação, tão caro à epistemologia da práxis em que se apoiam os trabalhos colaborativos de perspectiva sócio-histórico-cultural. Ao especificar como uma das ações do subprojeto a transposição das orientações curriculares produzidas, em regra, por atores alheios aos mesmos contextos que se busca transformar, o caráter colaborativo do trabalho ganha tons que remetem ao discurso de autoridade (BAKHTIN, 1981). Nesse caso, pode-se considerar que a inovação a que se refere o subprojeto não é aquela que decorre do reconhecimento dos fatores e fronteiras sociais, políticas, econômicas, culturais em que se engendram as práxis, mas aquela que busca impor, por meios mais participativos, práticas que podem ser entendidas como hegemônicas por se apoiarem em conhecimentos definidos como válidos por sujeitos que ocupam posições de privilégio nas relações de poder. O espaço discursivo criado por aquilo que se espera da academia serve aqui ao reforço do ethos formador-universidade.

Nesta direção, cabe analisar o apagamento dos papéis do professor de professores, normalmente denominado de formador ou, como dissemos, de supervisor de estágio. A descrição das ações do subprojeto contempla professores em serviço (aqui denominados professores supervisores) e professores em formação inicial (bolsistas, neste caso) conhecendo e analisando o contexto escolar, desenvolvendo práticas de inovação curricular, transpondo as orientações curriculares para esta prática. Embora o conceito de ensino colaborativo, apresentado no texto, pressuponha a participação do professor formador (ROTH; TOBIN, 2002), esta não é explicitamente refletida no discurso. Ao contrário, ao especificar que o subprojeto pretende fomentar o desenvolvimento de práticas de ensino colaborativo envolvendo professores supervisores e bolsistas de iniciação à docência, reforça-se a ideia de que estes são os agentes desta prática, sem que possa conhecer quais seriam, neste contexto, os papéis do formador.

Grosso modo, ensino colaborativo requer uma prática longitudinal com vistas a romper com as práticas individualistas e com as propostas monologizantes da formação tradicional e a ressignificar os papéis sociais e institucionalmente cristalizados. Deste modo, realizase nas ações em que professor de professores, professor colaborador e professor novato planejam, executam e avaliam juntos todo o trabalho 
realizado, compartilhando, assim, a responsabilidade pelos resultados alcançados. Este modelo de desenvolvimento profissional se engendra a partir da "reorganização de práticas, mediadas pela linguagem, em atividades que envolvem todos os participantes da discussão" (MAGALHÃES, 2010, p. 777), isto é, forja-se em contextos em que os sujeitos refletem sobre as experiências vivenciadas na práxis, e juntos, procuram buscar soluções a fim de superar as contradições que se colocam. Assim posto, o uso do termo 'ensino colaborativo' na proposta vincula-se a uma perspectiva que implica, primordialmente, na ressignificação de papéis; de modo especial, na ressignificação do papel do formador e no seu deslocamento também como professor da educação básica.

Já dissemos que os modos como os professores e o conhecimento estão posicionados nas práticas sociais discursivas que fundamentam este subprojeto marcam os limites e potencialidades de suas ações e criações. Nesse sentido, o deslocamento do professor da rede de ensino - de seu lugar de professor que cede suas aulas ao estagiário para o lugar de professor que atua na formação deste futuro profissional como supervisor - traz a possibilidade de que os alunos aprendam a ensinar no contexto de colaboração de mudança curricular, enquanto estes mesmos professores aprendam a transformar suas ações no contexto de parceria com os alunos. Por outro lado, a ausência de papéis definidos para o professor formador sinaliza uma concepção que busca manter seu status quo, historicamente dado como aquele cuja posição de poder e responsabilidades estão livres de serem explicitadas ou questionadas.

Dentro deste subprojeto, duas equipes de trabalho foram formadas para atuar em dois colégios públicos da cidade de Londrina, sendo que cada uma delas é formada por 1 professora de professores, 10 professores novatos e 1 professora colaboradora.

Espera-se, assim, como contribuição,

colaborar para o desenvolvimento de atitudes, conhecimentos e habilidades do professor de língua estrangeira que o possibilite lidar com os desafios da educação básica; implementar currículo diferenciado para formação de professores de inglês em uma perspectiva crítico-colaborativa;construir currículo diferenciado 
para língua inglesa em uma perspectiva de multiletramento crítico;promover o desenvolvimento social da região envolvida, por meio da exploração da linguagem em contextos significativos para os jovens e crianças do ensino básico;estabelecer vínculos produtivos com comunidade(s) escolares;contribuir para uma cultura de formação de professores situada e colaborativa, que permita o desenvolvimento tanto do aluno-professor, do professor supervisor e do contexto escolar. (Subprojeto)

Aqui também o discurso traz marcas da relação simétrica que coloca o formador no papel de quem tem mais a ensinar do que a aprender. É o professor da escola básica quem deverá, em última instância, ter suas atitudes, conhecimentos e habilidades desenvolvidos e, assim, tornar-se capaz de lidar com os desafios da educação. Do mesmo modo, a criação do modelo de formação situada e colaborativa é pensada de forma a contribuir para o desenvolvimento do futuro professor, do professor supervisor e do contexto escolar que, posto no singular, leva a presumir que seja o da educação básica.

No entanto, ainda que posto numa perspectiva genérica, o texto revela preocupações com o contexto local em que estão inseridas as comunidades escolares quando faz referência ao desenvolvimento social da região em que atuam e da formação de vínculos produtivos com seus agentes.

\section{As possibilidades mediadas pelas condições dominantes}

Ao falarmos sobre formação colaborativa de professores, estamos prioritariamente buscando romper com as práticas individualistas e com as propostas monologizantes da formação dita tradicional. Além disso, estamos, também, buscando a (re)significação dos papéis sociais institucionalmente cristalizados, em que o professor da universidade pode ser visto como o detentor do conhecimento e os alunos e o professor colaborador como os receptores deste conhecimento. Isto é, embora os modos de participação colaborativa de todos os envolvidos variem muito, conforme suas possibilidades e objetivos, todos participam de alguma forma. A nosso ver, aqui está uma importante contribuição da perspectiva sócio-histórico-cultural 
para a formação de professores, pois é por meio da multiplicidade de vozes que florescem sob as condições da diversidade que novas aprendizagens são potencializadas de forma emancipatória (MATEUS, 2007).

Podemos ressaltar, com base na análise aqui feita, que o programa representa, de modo geral, a continuidade de modelos de formação inicial e contínua de professores de Inglês vivenciados pela instituição e, agora, formalizados nesta proposta governamental. Representa, também, possibilidades para o fortalecimento de uma cultura colaborativa na formação de professores. Representa, ainda, uma resposta às demandas de melhoria da qualidade dos cursos de formação, do ensino na educação básica e dos contextos nos quais as comunidades escolares estão inseridas.

Em relação aos papéis dos envolvidos, o programa se pauta no discurso que almeja promover uma organização menos hierárquica que a historicamente produzida, pois há uma ressignificação do professor colaborador como supervisor e a possibilidade, assim, de formação continuada e de um novo posicionamento identitário: de professor, normalmente apenas avaliado nas aulas de estágio, para responsável pelo processo de formação de novos professores. Por sua vez, o apagamento dos papéis do formador, tomados, por esta razão, como dados e imutáveis revelam um padrão complementar de colaboração e convidam a refletir sobre o desafio da mutualidade no trabalho colaborativo. Assim, se por um lado, há uma forte preocupação com a aproximação dos mundos da universidade-escola, da valorização da escola como lócus de formação para futuros professores e do reposicionamento do professor da educação básica como supervisor, por outro, não objetiva reposicionar o trabalho do professor formador, agente igualmente passível de transformações.

Busca-se, portanto, a aproximação entre os mundos universidade-escola por meio de práticas colaborativas como forma de superação para a questão da produção do conhecimento, mas a relação hierárquica da universidade com a escola é dada como certa, natural e esperada. Nesse sentido, é importante reconhecer que os movimentos de ruptura se dão mediados pela dialética transformaçãopermanência. A herança cultural que valoriza o conhecimento científico sobre o cotidiano, o papel do formador sobre o do professor, a 
conquista individual sobre a coletiva parecem exercer grande influência sobre os modos como a organização deste modelo colaborativo se deu. Nestes casos, o risco que se corre é o de não sermos capazes de romper com os modos de produção de conhecimento, historicamente processados de forma verticalizada, do formador para o professor, do professor para o aluno e assim continuamente no interior das redes sociais de poder.

\section{À guisa de considerações infinitas}

Os indícios de que modelos colaborativos para a formação de professores sejam possibilitados por meio do reconhecimento da escola como lócus de formação e desenvolvimento profissional trazem olhares de esperança. Ao mesmo tempo, tais iniciativas requerem um olhar cauteloso, crítico, responsável e preocupado com práticas que transformem a realidade social. Isso se quisermos que as ações realizadas não sejam apenas uma roupa nova para práticas antigas.

Desse modo, acreditamos que as considerações aqui realizadas contribuem para uma reflexão sobre os pressupostos do programa e para o redirecionamento das práticas dos envolvidos, principalmente se estas se pretendem colaborativas. Isso porque um dos maiores desafios do trabalho colaborativo está em que os envolvidos abram mão de seus papéis sociais, historicamente (re)produzidos.

Salientamos, ao mesmo tempo, a necessidade de que mais pesquisas sejam realizadas para melhor compreensão de possibilidades e limitações de iniciativas como esta que analisamos. Propomos, portanto, como agenda de pesquisa algumas questões que necessitam ser investigadas para um melhor entendimento dos resultados dessa proposta. Entre elas:

- Quais identidades profissionais estão sendo produtos desta relação?;

- Como as ações do PIBID têm ajudado na elevação da qualidade do ensino da educação básica?;

- Como tais ações têm sido organizadas?;

- Como o currículo da disciplina de inglês tem sido transformado na práxis?; 
- O que futuros professores aprendem nesta organização de trabalho?;

- Que tipo de conhecimento é esse?;

- Como professores colaboradores estão encarando seu posicionamento como supervisores?;

- Quais são as transformações nas identidades do formador ao trabalhar em contextos colaborativos?;

- Os saberes dos professores colaboradores estão sendo reconhecidos? Em quais momentos?;

- Como o currículo dos cursos de formação de professores tem sido ressignificado devido às práxis vivenciadas?;

- Quais as relações estabelecidas entre os envolvidos?;

- Como esses profissionais envolvidos nesta organização de trabalho conseguem transformar a escola?.

Embora cientes de que não haja uma prescrição em como se trabalhar colaborativamente, olhando de nossa janela, uma cultura de formação colaborativa de professores envolveria o reconhecimento da necessidade de se propiciar a construção do conhecimento por meio do diálogo, da negociação de diferenças, da reorganização dos papéis dos envolvidos, da mutualidade de papéis, do suporte e confiança no outro e uma constante disposição de repensar a prática. Ainda que se possa supor que essas ações, em tese, se façam presentes no decorrer das práticas do subprojeto, a análise a que se pretende este texto deixa ver o discurso que reflete e refrata sentidos de abordagens tradicionais em programas de formação de professores (MATUSOV; HAYES, 2002). Além disso, a cultura da formação colaborativa envolveria o reconhecimento de que a formação está intimamente conectada com a percepção de prazer e recompensa pelo trabalho realizado e com o reconhecimento de que a emoção e a amizade são partes intrínsecas de todo e qualquer processo colaborativo. Acima de tudo, modelos de formação colaborativa, para se constituírem como herança cultural, precisam se dar no interior da práxis. Como argumentam Mateus e Piconi (2007), não se pode formar professores capazes de diálogo fora de práticas dialógicas, assim como não se pode romper com relações de poder sem a legitimação do outro.

Pelo que se pode ver da janela, o PIBID representa paisagem de esperança. 


\section{Referências}

AUERBACH, E. Participatory action research. In: CUMMING, A. (Ed.). Alternatives in TESOL research: descriptive, interpretive, and ideological orientations. TESOL QUARTERLY, v. 28, n. 4, p. 673703, Winter 1994.

BAKHTIN, M. M. The dialogic imagination: four essays by M.M. Bakhtin. Trad. Caryl Emerson; Michael Holquist. Austin: University of Texas Press, 1981.

BREDO, E.; FEINBERG, W. The critical approach to social and educational research. In: . (Eds.). Knowledge and Values in Social and Educational Research. Philadelphia: Temple University Press, 1982. p. 271-291.

CAMERON, D. et al. Researching Language: issues of power and method. London/New York: Routledge, 1992.

CAPES. Programa Institucional de Bolsa de Iniciação à Docência. PIBID. 2010. Disponível em: <http://www.capes.gov.br/images/ stories/download/ PIBID/2010.pdf > . Acesso em: 30 ago. 2010.

COLE, A.L.; KNOWLES, J.G. Teacher development partnership research: a focus on methods and issues. American Educational Research Journal, v. 30, n. 3, p. 473-495, Fall 1993.

EL KADRI, M.S.; MATEUS, E.; PASSONI, T.P. Dois modelos de estágio: contribuições e possibilidade de aprendizado na formação inicial de professores. Entretextos (UEL), Londrina, v. 9, p. 85-106, 2009.

ENGESTRÖM, Y. Activity Theory and individual and social transformation. In: ; MIETTINEM, R.; PUNAMAKI, R. (Eds.). Perspectives on activity theory. Cambridge-UK: Cambridge University Press, 1999, p. 19-38.

FEIMAN-NEMSER, S. Teacher preparation: structural and conceptual alternatives. In: HOUSTON, W.R. (Ed.). Handbook of research on teacher 
education. New York: Macmillan, 1990. p. 212-233. Disponível em: <http://ncrtl.msu.edu/http/ipapers/html/pdf/ip895.pdf >. Acesso em: 20 out. 2004.

FULLAN, M.; HARGREAVES, A. A escola como organização aprendente: buscando uma educação de qualidade. Trad. Regina Garcez. Porto Alegre: Artes Médicas, 2000.

FURTOSO, V. et al. Parceria universidade/escolas: conquistas e desafios na formação de professores. In: MATEUS, E.; QUEVEDOCAMARGO, G.; GIMENEZ, T. (Orgs.). Ressignificações na formação de professores: rupturas e continuidades. Londrina: Eduel, 2009. p. 45-60.

GAFFURI, P.; MATEUS, E. (Re)significando o aprender: rompendo barreiras do universo universidade-escola. In: CONGRESSO LATINO-AMERICANO DE FORMAÇÃO DE PROFESSORES DE LÍNGUAS, 3., Taubaté, 2010. Anais.... Taubaté: Unitau, 2010. p. 315-316.

GIMENEZ, K.; MATEUS, E. Rompendo barreiras num projeto de aprendizagem sem fronteiras. TELLES, J. (Org.). Formação inicial e continuada de professores de línguas: dimensões e ações na pesquisa e na prática. Campinas: Pontes, 2009. p. 113-136.

GIMENEZ, T. (Org.) Os sentidos do Projeto NAP. Londrina: EDUEL, 1999. p. 33-40.

HOLZMAN, L.; KARLINER, S. Developing a psychology that builds community and respects diversity. In: CULTURAL DIVERSITY IN PSYCHOLOGY: IMPROVING SERVICES BY ADDRESSING PUBLIC POLICY, Washington-DC, Aug. 2005. Disponível em: <http://lchc.ucsd.edu/mca/Paper/index.html'http://lchc.ucsd.edu/ mca/Paper/index.html>. Acesso em: 8 fev. 2011.

JOHNSON, K. The sociocultural turn and its challenges for second language teacher education. TESOL QUARTERLY, v. 40, n. 1, p. 235257, Mar. 2006. 
Second language Teacher Education: a sociocultural perspective. New York: Routlegde, 2009. JOHN-STEINER, V. Creative collaboration. New York: OUP, 2000.

KINCHELOE, J.L. A formação do professor como compromisso político: mapeando o pós- moderno. Porto Alegre: Artes Médicas, 1997.

LEONTIEV, A. Le Développment du psychisme. Paris: Editions Sociales, 1959.

- Activity, consciousness, and personality. Progress Publishers, 1978.

Disponível em: <http://lchc.ucsd.edu/MCA/Paper/leontev>. Acesso em: 11 jul. 2003.

- Uma contribuição a teoria do desenvolvimento da psique infantil. In: VIGOTSKI, L.S.; LURIA, A.R.; LEONTIEV, A.N. Linguagem, desenvolvimento e aprendizagem. Trad. Maria da Penha Villalobos. São Paulo: Ícone; Editora da Universidade Estadual de São Paulo, 1998. p. 59-83.

MAGALHÃES, M.; FIDALGO, S. Critical collaborative research: focus on the meaning of collaboration and on mediational tools. RBLA, Belo Horizonte, v. 10, n. 3, p. 773-797, 2010.

MATEUS, E. Pesquisa colaborativa e seus significados para os envolvidos em um programa de formação docente. In: ENCONTRO NACIONAL DE DIDÁTICA E PRÁTICA DE ENSINO ENDIPE, 12., Curitiba, 2004. Anais... Curitiba: Pontifícia Universidade Católica do Paraná, 2004. v. 1. p. 1978-1986.

- Atividade de aprendizagem colaborativa e inovadora de professores: ressignificando as fronteiras dos mundos universidade-escola. 2005. 327fl. Tese (Doutorado em Linguística Aplicada e Estudos da Linguagem) -Pontifícia Universidade Católica de São Paulo, São Paulo. 2005.

- Aprendizagem colaborativa de professores de inglês: uma experiência de encontro da universidade com a escola. In: 
ENCONTRO NACIONAL DE DIDÁTICA E PRÁTICA DE ENSINO - ENDIPE, 13., Recife, 2006. Anais... Recife: Universidade Federal de Pernambuco, 2006. p. 1479-1496.

Aprendizagem sem Fronteiras: ressignificando os limites da formação inicial e contínua de professores. In: ABRAHÃO, M.H.; GIL, G.; RAUBER, A.C. (Orgs.). In: CONGRESSO LATINOAMERICANO SOBRE FORMAÇÃO DE PROFESSORES DE LÍNGUAS, 1., Florianópolis, 2007. Anais... Florianópolis: UFSC, 2007. p. 672-689. Disponível em: <http://www.cce.ufsc.br/ clafpl/ pagina_principal1.htm $>$.

- Práxis colaborativa e as possibilidades de ser-com-o-outro. In: DAMIANOVIC, M. C. et al. (Orgs.) Vygotsky: uma (re)visita no início do século XXI. São Paulo: Andross, 2009a. p. 17-52.

. Em busca de outros modos de com-viver. In:

QUEVEDO-CAMARGO, G.; GIMENEZ, T. (Orgs.). Ressignificações na formação de professores: rupturas e continuidades. Londrina: Eduel, 2009b. p. 61-80.

- Para além do espelho: reflexão como produção de novas práticas sociais. In: BARROS, S.M.; ASSIS-PETERSON, A.A. Formação crítica de professores de línguas: desejos e possibilidades. São Carlos: Pedro e João Editores, 2010. p. 27-39.

. ; PEZENTE, R.; ROSA, K. A construção da colaboração e seus significados para os envolvidos na pesquisa. In: INTERCÂMBIO DE PESQUISAS EM LINGÜÍSTICA APLICADA - INPLA, 13., São Paulo, 2003. Caderno de Resumos. São Paulo: LAEL/PUC, 2003. p. 74.

. ; PICONI, L. Aprendizagem colaborativa de professores em formação inicial e contínua: investigando práticas discursivas. In: CONGRESSO BRASILEIRO DE LINGÜÍSTICA APLICADA, 8., Brasília, 2007. Anais... Brasília: CBLA, 2007. 
; Aprendizagem colaborativa de professores em formação inicial e continuada: investigando as práticas discursivas. In: FERNANDES, L.C. (Org.). Interação: práticas de linguagem. Londrina: Eduel, 2009. p. 133-152.

.; QUEVEDO-CAMARGO, G.; GIMENEZ, T. (Orgs.). Ressignificações na formação de professores: rupturas e continuidades. Londrina: Eduel, 2009.

MATTOS, C.L.G. Etnografia crítica da sala de aula: o professor pesquisador e o pesquisador professor em colaboração. Educação e Sociedade, a. 16, n. 51, p. 299-311, ago. 1995.

MCLAREN, P.; GIROUX, H. Escrevendo das margens: geografias de identidade, pedagogia e poder. In: - (Org.). Multiculturalismo revolucionário: pedagogia do dissenso para o novo milênio. Trad. Márcia Moraes; Roberto Cotaldo Costa. Porto Alegre: Artes Médicas, 2000. p. 25-49.

MOITA LOPES, L.P. Oficina de lingüistica aplicada. Campinas: Mercado de Letras, 1996.

ORTENZI, D. et al. Interação universidade-escola na formação de professores de inglês: experiências brasileira e norte-americana. In: ENCONTRO NACIONAL DE DIDÁTICA E PRÁTICA DE ENSINO - ENDIPE, 12., Curitiba, 2004. Anais... Curitiba: Pontifícia Universidade Católica do Paraná, 2004. v. 1. p. 239-245.

PENNYCOOK, A. The cultural politics of English as an international language. New York: Longman, 1994. p. 1-37.

PERRENOUD, P. Ensinar: agir na urgência, decidir na incerteza. Saberes e competências em uma profissão complexa. Porto Alegre: Artmed, 2001.

REIS, S. Os sentidos de uma proposta de ação e reflexão no ensino de língua inglesa em escolas públicas. In: GIMENEZ, T. (Org.) Os sentidos do Projeto NAP. Londrina: EDUEL, 1999. p. 33-40. 
ROTH, W.M.; TOBIN, K. Redesigning an "urban” teacher education program: an activity theory perspective. Mind, Culture and Activity, v. 9, n. 2, p. 108-131, 2002.

; Coteaching: from praxis to theory. Teachers and Teaching: theory and practice, v. 10, n. 2, p. 161-180, Apr. 2004.

SCHÖN, D.A. Educating the reflective practitioner. Jossey: Bass Publishers, 1987. p. 3-40.

VADEBONCOEUR, J. A. Child development and the purpose of education: a historical context for constructivism in teacher education. In: RICHARDSON, V. (Ed.). Constructivist teacher education: building new understandings. Washington: The Falmer Press, 1997. p. 15-37.

VYGOTSKY, L.S. Thought and language. Cambridge: MIT Press, 1962 [1934]. Parcialmente disponível em: <http://www.marxists.org/ archive/vygotsky/works/words/index.htm>. Acesso em: 13 jun. 2002.

Interaction between learning and development. In: COLE, M. et al. (Orgs.). Mind in society. Cambridge: Cambridge University Press, 1978 [1930].

. The collected works of L.S. Vygotsky Volume 4: The history of the development of higher mental functions. New York/London: Plenum Press, 1997.

- A formação social da mente: o desenvolvimento dos processos psicológicos superiores. 6. ed. Trad. José Cipolla Neto et al. São Paulo: Martins Fontes, 1998. [Orgs. Michael Cole et al., 1978]. 